\title{
ANALISIS TINGKAT EMISI PADA CEROBONG ASAP PABRIK SEMEN TONASA PANGKEP
}

\section{EMISSION ANALYSIS ON SMOKE STACK FACTORY TONASA CEMENT PANGKEP}

\author{
Muhammad Anshari Caronge ${ }^{* 1)}$, M. Wihardi Tjarong ${ }^{1)}$, dan Rita Irmawaty ${ }^{1)}$ \\ ${ }^{1)}$ Departemen Teknik Lingkungan, Universitas Hasanuddin, \\ Jl. Poros Malino KM. 6, Bontomarannu, Gowa, 92171 \\ ${ }^{*}$ E-mail: ari.caronge@gmail.com
}

\begin{abstract}
Abstrak
Industri semen merupakan salah satu penyumbang polusi udara terbesar di dunia karena tingkat konsumsi energi dan potensi emisi debu. Hal ini menjadi faktor utama sumber polusi udara. Emisi udara dari industri semen mengandung zat-zat kimia yang berbahaya, seperti total partikel, $\mathrm{CO}_{2}, \mathrm{NO}_{2}, \mathrm{SO}_{2}$, dan opasitas. Dampak dari emisi akibat industri semen tidak hanya berpengaruh pada kesehatan manusia saja, tetapi juga pada lingkungan sekitar tempat produksi semen. Oleh karena itu, perlu adanya analisis emisi pada pabrik produksi semen untuk mengetahui efeknya terhadap kesehatan dan lingkungan sekitar. Metode pengujian yang digunakan dalam penelitian ini adalah penentuan total partikel secara isokinetik, uji SOx menggunakan metode turbidimetri, uji kadar nitrogen dioksida $\left(\mathrm{NO}_{2}\right)$ dengan metode Griess Saltzman, uji $\mathrm{CO}_{2}$ dengan cara analisis otomatik. Hasil uji emisi menunjukkan konsentrasi zat pencemar emisi masih berada di bawah Baku Mutu Emisi sesuai KEPMENKES-13/MENLH/1995 tentang Baku Mutu Emisi Tidak Bergerak.
\end{abstract}

Kata kunci: Emisi, Industri, Semen, Udara.

\begin{abstract}
The cement industry is one of the biggest contributors to the world's air pollution due to its energy consumption and dust emission. The emission from cement industry contains hazardous chemical substances such as total particle, $\mathrm{CO}_{2}, \mathrm{NO}_{2}, \mathrm{SO}_{2}$, and black dust. The impact of the cement industry emission does not only impact human health, but also the surrounding environment. Therefore, an analysis of the emission at a cement production company is necessary to find out about its impact on health and the environment. Test methods used in this research is determination of Total Particles by isokinetic, SOx test using turbidimetry method, test of Nitrogen Dioxide (NO2) level by Griess Saltzman method, $\mathrm{CO}_{2}$ test by automatic analysis. The emission test results showed that the emissions were still below the Standard of Emission Quality in accordance with KEPMENKES-13 / MENLH / 1995 on the Standard of Stationary Emission Quality.
\end{abstract}

Keywords: Air, Cement, Emission, Industry.

\section{PENDAHULUAN}

Industri semen merupakan salah satu penyumbang polusi udara terbesar di dunia karena tingkat komsumsi energi dan potensi emisi debu. Hal ini menjadi faktor utama sumber polusi udara. Emisi udara dari industri semen mengandung zat-zat kimia yang berbahaya bagi kesehatan dan lingkungan hidup, seperti $\mathrm{CO}, \mathrm{NO}, \mathrm{SO}$, partikel-partikel dan beberapa mikropolutan (Anand $d k k ., 2006$ ). Secara umum, jumlah emisi berkaitan erat dengan material dasar dan bahan bakar yang digunakan untuk memproduksi semen. Selain itu faktor transportasi dan proses ekstraksi bahan 
mentah secara tidak langsung mempunyai dampak yang sangat signifikan (Ernst and Lynn, 2011).

Sebagai penghasil semen terbesar di kawasan Indonesia Timur, maka perlu dilakukan analisis emisi untuk mengetahui tingkat emisi dan jenis-jenis pencemar yang terkandung pada cerobong asap PT. Semen Tonasa. Dampak dari emisi akibat industri semen tidak hanya berpengaruh pada kesehatan manusia saja, tetapi juga pada lingkungan sekitar tempat produksi semen.

Hampir 1/3 emisi karbon dioksida $\left(\mathrm{CO}_{2}\right)$ atau sekitar $2.370 \mathrm{Tg} \mathrm{CO}_{2}$ yang berada di udara berasal dari sektor perindustrian (Anand, $d k k$., 2006). Jumlah ini sekitar $43 \%$ dari total emisi $\mathrm{CO}_{2}$ dunia. Industri semen memiliki konstribusi sekitar 7\% dari emisi $\mathrm{CO}_{2}$ di dunia (Yeonbae dan Worrel, 2002). Estimasi sekitar 0,9-1 ton $\mathrm{CO}_{2}$ berasal dari produksi satu ton klinker berdasarkan tipe bahan bakar yang digunakan. Hoenig (2010) mengatakan bahwa 0,65-0,92 $\mathrm{kg} \mathrm{CO}$ dihasilkan dalam satu kilogram semen dengan menggunakan teknologi modern.

Emisi $\mathrm{CO}_{2}$ umumnya berasal dari proses pembakaran bahan bakar fosil dan proses kalsinasi batu kapur menjadi kalsium oksida $(\mathrm{CaO})$. Komposisi jenis gas yang dihasilkan dari cerobong pabrik semen memiliki konsentrasi yang berbeda-beda yang dapat dilihat pada Tabel 1 .

Tabel 1. Komposisi gas dari cerobong pabrik semen

\begin{tabular}{|c|l|}
\hline Komponen & \multicolumn{1}{|c|}{ Konsentrasi } \\
\hline $\mathrm{CO}_{2}$ & $14-33 \%(\mathrm{w} / \mathrm{w})$ \\
$\mathrm{NO}_{2}$ & $5-10$ \\
$\mathrm{NO}_{\mathrm{x}}$ & $<200-3000 \mathrm{mg} / \mathrm{Nm}^{3}$ \\
$\mathrm{SO}_{2}$ & $<10-3500 \mathrm{mg} / \mathrm{Nm}^{3}$ \\
$\mathrm{O}_{2}$ & $8-14 \%(\mathrm{v} / \mathrm{v})$ \\
\hline
\end{tabular}

(Sumber: Bosoaga $d k k ., 2009$ )

\section{Proses Pembuatan Semen}

- Proses Penyiapan Bahan Baku

Bahan baku utama semen diperoleh dari proses penambangan. Bahan baku berupa batu kapur dan tanah liat akan dihancurkan menggunakan crusher untuk memperkecil ukuran material agar mudah dalam proses penggilingan. Setelah itu, raw material akan mengalami proses pre-homogenisasi untuk memperoleh bahan baku yang homogen.

- Proses Pengolahan Bahan

Alat utama yang digunakan pada proses ini adalah Vertical Roller Mill (VRM). Media pengeringnya adalah udara panas yang berasal dari siklon pre-heater. Udara panas tersebut juga berfungi sebagai media pembawa bahan-bahan yang telah halus menuju proses selanjutnya.

- Proses Pembakaran

Alat utama yang digunakan untuk pemanasan awal bahan baku adalah suspension pre-heater. Setelah mengalami proses homogenisasi di blending silo, material terlebih dahulu akan ditampung ke dalam kiln. Alat utama yang digunakan adalah tanur putar (rotary kiln). Material akan mengalami pembakaran dari suhu rendah ke suhu tinggi. Bahan bakar yang digunakan adalah batu bara.

- Proses Penggilingan Akhir

Alat utama yang digunakan pada proses ini adalah tube mill. Bahan baku yang telah dipanaskan kemudian dicampur dengan gipsum. Material yang sudah digiling kemudian diangkut menuju separator.

- Proses Pengemasan (Packing)

Silo semen tempat penyimpanan produk dilengkapi dengan sistem aerasi untuk menghindari penggumpalan semen yang dapat disebabkan oleh air dari luar. Setelah itu dilakukan proses pengemasan agar semen lebih mudah dijual kepasaran dalam bentuk sak.

\section{METODA}

Penelitian ini dilaksanakan di pabrik PT. Semen Tonasa yang berlokasi di Kabupaten 
Pangkep, Sulawesi Selatan pada saat pengujian emisi periode Desember 2011.

\section{Metode Pengambilan Sampel}

Metode pengambilan sampel dilakukan berdasarkan SNI 19-7117.2-2005 tentang Penentuan Lokasi dan Titik-Titik Lintas Pengambilan Contoh Uji Partikel. Pemilihan lokasi dilaksanakan pada suatu tempat paling sedikit 8 kali diameter cerobong dari aliran bawah (hulu) dan 2 kali diameter dari aliran atas (hilir) dan bebas dari gangguan aliran seperti belokan, pelebaran, atau penyempitan aliran turbulen. Lokasi alternatif dapat dipilih pada posisi 2 kali diameter cerobong dari aliran bawah atau 0,5 kali diameter cerobong dari aliran atas.

\section{Metode Pengujian}

Metode pengujian yang dilakukan untuk total partikel, sulfur dioksida $\left(\mathrm{SO}_{2}\right)$, nitrogen dioksida $\left(\mathrm{NO}_{2}\right)$, karbon monoksida $(\mathrm{CO})$, dan opasitas berdasarkan SNI.

1. SNI 19-7117.12-2005 : Penentuan total partikel secara isokinetik.

2. SNI 19-7117.3.1-2005 : Cara uji oksidaoksida sulfur (SOx) dengan metode turbidimetri menggunakan spektrofotometer.

3. SNI 19-7119.2-2005 : Cara uji kadar nitrogen dioksida $\left(\mathrm{NO}_{2}\right)$ dengan metode Griess Saltzman menggunakan spektrofotometer.

4. SNI 19-7117.10-2005: Cara uji konsentrasi $\mathrm{CO}, \mathrm{CO}_{2}$, dan $\mathrm{O}_{2}$ dengan peralatan analisis otomatik.

5. SNI 19-7117.11-2005 : Cara uji opasitas menggunakan skala Ringelmann untuk asap hitam.

6. SNI 19-7117.2-2005 : Penentuan lokasi dan titik-titik lintas pengambilan contoh uji partikel.

\section{Perhitungan Kadar Sulfur Dioksida $\left(\mathrm{SO}_{2}\right)$}

Jumlah ion asam sulfat akan diperoleh dari kurva kalibrasi dan konsentrasi oksida sulfur dalam contoh uji gas dihitung dengan rumus sebagai berikut:

$$
\mathrm{C}=\frac{\mathrm{BMSO}_{2}}{\mathrm{BMSO}_{4}} \times \frac{(\mathrm{a}-\mathrm{b}) \times 250 / 50}{\mathrm{Vs}} \times 1000 \times \mathrm{mg} / \mathrm{m}^{3}
$$

Keterangan :

$\mathrm{C}=$ konsentrasi sulfur dioksida $\left(\mathrm{mg} / \mathrm{m}^{3}\right)$

Vs = volume contoh uji yang terambil (ml)

$\mathrm{a}=$ jumlah ion asam sulfat yang diperoleh dari kurva kerja (mg)

$\mathrm{b}=$ jumlah ion asam sulfat yang diperoleh dari uji blanko (mg)

*) $1 \mathrm{ml}$ asam sulfat $1 / 250 \mathrm{~N}$ sebanding dengan $0,2 \mathrm{mg}$ ion $\mathrm{SO}_{4}$.

\section{Perhitungan Nitrogen Dioksida $\left(\mathrm{NO}_{2}\right)$}

Jumlah total kadar nitrogen dioksida $\left(\mathrm{NO}_{2}\right)$ didapat dari perhitungan sebagai berikut:

$$
\mathrm{C}=\frac{\mathrm{V}}{\mathrm{Vs}} \times 1000 \times \frac{46}{24,45}
$$

Keterangan:

$\mathrm{C} \quad=$ konsentrasi nitrogen dioksida $\left(\mathrm{mg} / \mathrm{Nm}^{3}\right)$

$\mathrm{V}=$ volume nitrogen dioksida $(\mathrm{ml})$

Vs = volume contoh uji gas yang terambil (ml) pada $25^{\circ} \mathrm{C}(760 \mathrm{mmHg})$

$46=$ berat molekul nitrogen dioksida $\left(\mathrm{NO}_{2}\right)$

$24,45=$ volume gas ideal $\left(25^{\circ} \mathrm{C}\right.$, $760 \mathrm{mmHg}$ ).

Perhitungan Karbon Monoksida (CO) Jumlah kadar karbon monoksida yang terambil dapt dihitung pada kondisi standar atmosferik $\left(25^{\circ} \mathrm{C}, 760 \mathrm{mmHg}\right)$ dengan menggunakan rumus sebagai berikut:

$$
V s=V \times \frac{298}{273+t} \times \frac{(P s+P m-P v)}{760}
$$

Keterangan:

Vs = Jumlah kadar karbon monoksida (L)

$\mathrm{V}=$ nilai pembacaan gas meter $(\mathrm{L})$ 
Ps =tekanan atmosfer udara (mmHg)

$\mathrm{Pm}=$ tekanan gauge pada gasmeter $(\mathrm{mmHg})$

$\mathrm{Pv}=$ tekanan uap jenuh pada temperature gas $\mathrm{t}^{0} \mathrm{C}(\mathrm{mmHg})$

$\mathrm{T}=$ suhu yang terbaca pada gasmeter $\left({ }^{0} \mathrm{C}\right)$

\section{HASIL DAN PEMBAHASAN}

Pengujian emisi ini dilaksanakan pada periode Desember 2011 di beberapa titik, yaitu pada Cerobong Batu Kapur, Cerobong Pendingin Terak, Cerobong Tanur Putar (kiln), Cerobong Coal Mill, dan Cerobong bahan bakar batu bara PLTU.

\section{Uji emisi cerobong pengering batu kapur (Limistone Dryer)}

Kandungan zat pencemar yang dihasilkan pada proses pengeringan batu kapur berada jauh di bawah standar Baku Mutu Emisi (Tabel 2). Hal ini disebabkan karena pada proses ini, kandungan zat pencemar hanya berasal dari coller dan pre-heater. Pada proses ini, terdapat alat vertical roller mill yang berfungsi untuk mengendalikan ukuran partikel yang boleh keluar, sedangkan ukuran partikel yang berukuran besar dikembalikan ke dalam raw mill untuk dihaluskan sampai ukurannya mencapai ukuran yang diharapkan.

Tabel 2. Hasil uji emisi cerobong pengering batu kapur (Limistone Dryer)

\begin{tabular}{|l|l|c|c|}
\hline No & \multicolumn{1}{|c|}{ Parameter } & $\begin{array}{c}\text { Konsentrasi } \\
\left(\mathrm{mg} / \mathrm{Nm}^{3}\right)\end{array}$ & $\begin{array}{c}\mathrm{BME} \\
\left(\mathrm{mg}^{2} \mathrm{Nm}^{3}\right)\end{array}$ \\
\hline 1 & Total partikel & 13,27 & 80 \\
\hline 2 & $\begin{array}{l}\text { Sulfur dioksida } \\
\left(\mathrm{SO}_{2}\right)\end{array}$ & 4,75 & 800 \\
\hline 3 & $\begin{array}{l}\text { Nitrogen } \\
\text { dioksida }\left(\mathrm{NO}_{2}\right)\end{array}$ & 6,14 & 1.000 \\
\hline 4 & $\begin{array}{l}\text { Karbon } \\
\text { monoksida }(\mathrm{CO})\end{array}$ & 2,19 & - \\
\hline 5 & Opasitas & 5 & $20 \%$ \\
\hline
\end{tabular}

Uji emisi cerobong pendingin kerak(Grate Cooler)

Hasil uji emisi pada cerobong pendingin kerak (Grate Cooler) masih berada dibawah standar Baku Mutu Emisi yang dapat dilihat pada Tabel 3. Hal ini disebabkan karena pada proses ini hanya terjadi pendinginan dan menggunakan alat pendingin yang memiliki 9 kompartemen yang memanfaatkan udara luar untuk proses pendinginan.

Tabel 3. Hasil uji emisi cerobong pendingin kerak (Grate Cooler)

\begin{tabular}{|l|l|c|c|}
\hline $\mathrm{No}$ & Parameter & $\begin{array}{c}\text { Konsentrasi } \\
\left(\mathrm{mg} / \mathrm{Nm}^{3}\right)\end{array}$ & $\begin{array}{c}\mathrm{BME} \\
\left(\mathrm{mg} / \mathrm{Nm}^{3}\right)\end{array}$ \\
\hline 1 & Total partikel & 19,84 & 80 \\
\hline 2 & $\begin{array}{l}\text { Sulfur dioksida } \\
\left(\mathrm{SO}_{2}\right)\end{array}$ & 3,92 & 800 \\
\hline 3 & $\begin{array}{l}\text { Nitrogen } \\
\text { dioksida }\left(\mathrm{NO}_{2}\right)\end{array}$ & 3,14 & 1.000 \\
\hline 4 & $\begin{array}{l}\text { Karbon } \\
\text { monoksida }(\mathrm{CO})\end{array}$ & 1,59 & - \\
\hline 5 & Opasitas & 5 & $20 \%$ \\
\hline
\end{tabular}

\section{Uji emisi cerobong Tanur Putar (Kiln)}

Hasil uji emisi pada cerobong Tanur Putar (Kiln) masih berada di bawah Baku Mutu Emisi (Tabel 4). Konsenstrasi emisi yang didapatkan sangat tinggi karena pada proses ini terjadi proses kalsinasi dan pembakaran material dari suhu yang rendah ke suhu yang tinggi yakni berkisar $800-900^{\circ} \mathrm{C}$, tetapi konsentrasi emisi bisa ditekan karena adanya alat gas analyzer yang berfungsi untuk mengendalikan kadar $\mathrm{O}_{2}, \mathrm{CO}_{2}$, dan $\mathrm{NOx}$ pada gas buang jika terjadi kelebihan atau kekurangan, maka jumlah bahan bakar dan udara dapat dikendalikan.

Tabel 4. Hasil uji emisi Cerobong Tanur Putar (Kiln)

\begin{tabular}{|l|l|c|c|}
\hline No & \multicolumn{1}{|c|}{ Parameter } & $\begin{array}{c}\text { Konsentrasi } \\
\left(\mathrm{mg} / \mathrm{Nm}^{3}\right)\end{array}$ & $\begin{array}{c}\mathrm{BME} \\
\left(\mathrm{mg} / \mathrm{Nm}^{3}\right)\end{array}$ \\
\hline 1 & Total partikel & 40,22 & 80 \\
\hline 2 & $\begin{array}{l}\text { Sulfur dioksida } \\
\left(\mathrm{SO}_{2}\right)\end{array}$ & 15,79 & 800 \\
\hline 3 & $\begin{array}{l}\text { Nitrogen } \\
\text { dioksida }\left(\mathrm{NO}_{2}\right)\end{array}$ & 11,37 & 1.000 \\
\hline 4 & $\begin{array}{l}\text { Karbon } \\
\text { monoksida }(\mathrm{CO})\end{array}$ & 5,28 & - \\
\hline 5 & Opasitas & 15 & $20 \%$ \\
\hline
\end{tabular}




\section{Uji emisi cerobong PLTU Bahan Bakar}

\section{Batu Bara}

Hasil uji emisi pada Cerobong PLTU Bahan Bakar Batu Bara menunjukkan hasil yang sangat tinggi, namun masih berada di bawah Baku Mutu Emisi yang dapat dilihat pada Tabel 5. Tingginya konsentrasi yang dihasilkan karena di PLTU merupakan sumber pembangkit listrik dan sumber bahan bakar pada proses rotary kiln.

Tabel 5. Hasil uji emisi Cerobong PLTU Bahan Bakar Batu Bara

\begin{tabular}{|l|l|c|c|}
\hline No & \multicolumn{1}{|c|}{ Parameter } & $\begin{array}{c}\text { Konsentrasi } \\
\left(\mathrm{mg} / \mathrm{Nm}^{3}\right)\end{array}$ & $\begin{array}{c}\text { BME } \\
\left(\mathrm{mg} / \mathrm{Nm}^{3}\right)\end{array}$ \\
\hline 1 & Total partikel & 74,27 & 80 \\
\hline 2 & $\begin{array}{l}\text { Sulfur dioksida } \\
\left(\mathrm{SO}_{2}\right)\end{array}$ & 46,45 & 800 \\
\hline 3 & $\begin{array}{l}\text { Nitrogen } \\
\text { dioksida }\left(\mathrm{NO}_{2}\right)\end{array}$ & 24,61 & 1.000 \\
\hline 4 & $\begin{array}{l}\text { Karbon } \\
\text { monoksida }(\mathrm{CO})\end{array}$ & 5,13 & - \\
\hline 5 & Opasitas & 15 & $20 \%$ \\
\hline
\end{tabular}

\section{Analisis Konsentrasi Uji Emisi dalam Estimasi Waktu Standar ISPU}

Selain menghitung emisi setiap periode (3 bulan) untuk sumber tidak bergerak, PT. Semen Tonasa juga menghitung pencemaran udara berdasarkan batas Indeks Standar Pencemaran Udara (sumber bergerak) yang dapat dilihat pada Tabel 6 .
Tingkat pencemar $\mathrm{SO}_{2}$ tertinggi terdapat pada zona IV sebesar 14,29 $\mu \mathrm{g} / \mathrm{m}^{3}$, sedangkan tingkat pencemar terendah terdapat di zona III sebesar $1,13 \mu \mathrm{g} / \mathrm{m}^{3}$ yang dapat dilihat pada Tabel 6. Pada pengujian $\mathrm{SO}_{2}$ di semua zona dikategorikan baik karena berada pada rentang $0-50 \mu \mathrm{g} / \mathrm{m}^{3}$, namun mengakibatkan luka pada beberapa spesies tumbuhan akibat kombinasi dengan $\mathrm{O}_{3}$.

Tingkat pencemar TSP tertinggi terdapat pada zona III sebesar $35,55 \mu \mathrm{g} / \mathrm{m}^{3}$, sedangkan tingkat pencemar terendah terdapat di zona I sebesar $23,7 \mu \mathrm{g} / \mathrm{m}^{3}$ yang dapat dilihat pada Tabel 6. Pada pengujian TSP di semua zona dikategorikan baik karena berada pada rentang $0-50 \mu \mathrm{g} / \mathrm{m}^{3}$ dan tidak mengakibatkan efek sama sekali.

Tingkat pencemar $\mathrm{CO}$ tertinggi terdapat pada zona I, zona II, dan zona IV sebesar 4,5 $\mu \mathrm{g} / \mathrm{m}^{3}$, sedangkan tingkat pencemar terendah terdapat di zona III dan zona V sebesar 2,8 $\mu \mathrm{g} / \mathrm{m}^{3}$ yang dapat dilihat pada Tabel 6. Pada pengujian $\mathrm{CO}$ di semua zona dikategorikan baik karena berada pada rentang $0-50 \mu \mathrm{g} / \mathrm{m}^{3}$ dan tidak mengakibatkan efek sama sekali.

\section{KESIMPULAN}

Zat pencemar yang terkandung dalam cerobong asap PT. Semen Tonasa terdiri dari total partikel, sulfur dioksida $\left(\mathrm{SO}_{2}\right)$, nitrogen dioksida $\left(\mathrm{NO}_{2}\right)$, karbon monoksida $(\mathrm{CO})$, dan opasitas. 
Tabel 6. Hasil Indeks Standar Pencemaran Udara (ISPU)

\begin{tabular}{|c|c|c|c|c|c|}
\hline Parameter & Area & $\begin{array}{c}\text { Waktu } \\
\text { Pengukuran } \\
\text { Standar( } \mu \mathrm{g} / \mathrm{m} 3)\end{array}$ & $\begin{array}{c}\text { Konsentrasi } \\
\text { Pemaparan } \\
\text { Standar } \\
(\mu \mathrm{g} / \mathrm{m} 3)\end{array}$ & $\begin{array}{l}\text { Hasil } \\
\text { ISPU } \\
(\mu \mathrm{g} / \mathrm{m} 3)\end{array}$ & $\begin{array}{c}\text { Kategori } \\
\text { ISPU }\end{array}$ \\
\hline \multirow{5}{*}{$\mathrm{SO}_{2}$} & Zona I & \multirow{5}{*}{24 Jam } & 3.92 & 2.45 & Baik \\
\hline & Zona II & & 5.59 & 3.49 & Baik \\
\hline & Zona III & & 1.82 & 1.13 & Baik \\
\hline & Zona IV & & 22.87 & 14.29 & Baik \\
\hline & Zona V & & 5.19 & 3.24 & Baik \\
\hline \multirow{5}{*}{ TSP } & Zona I & \multirow{5}{*}{24 Jam } & 23.7 & 23,7 & Baik \\
\hline & Zona II & & 183.33 & 26,19 & Baik \\
\hline & Zona III & & 35.55 & 35,55 & Baik \\
\hline & Zona IV & & 94.62 & 31,54 & Baik \\
\hline & Zona V & & 87.77 & 29,25 & Baik \\
\hline \multirow{5}{*}{$\mathrm{CO}$} & Zona I & \multirow{5}{*}{$8 \mathrm{Jam}$} & 0.45 & 4,5 & Baik \\
\hline & Zona II & & 0.45 & 4,5 & Baik \\
\hline & Zona III & & 0.28 & 2,8 & Baik \\
\hline & Zona IV & & 0.45 & 4,5 & Baik \\
\hline & Zona V & & 0.28 & 2,8 & Baik \\
\hline
\end{tabular}

\section{DAFTAR PUSTAKA}

Anand S, Vrat P, Dahiya R. (2006). Application of a system dynamics approach for assessment and mitigation of $\mathrm{CO} 2$ emissions from the cement industry. Journal of Environmental Management.

Bosoaga A, Masek O, Oakey J. (2009). CO2 Capture Technologies for Cement Industry. Energy Procedia 2009.

ErnstWorrell, Lynn Price. (2011).

CARBON DIOXIDE EMISSIONS

FROM THE GLOBA CEMENT INDUSTRY.

Hoenig V, Hoppe H, Emberger B. (2010).Carbon capture technology options and potentials for the cement industry. Tannenstrasse: European Cement Research Academy.

Yeonbae K, Worrell E. (2002). CO2 emission trends in the cement industry: an international comparison. Mitigation and Adaptation Strategies for Global Change. 